\title{
Mobile path loss slope for Indian suburban areas
}

\author{
Major B. Bhikshapathy ${ }^{1}$ V.M. Pandharipande ${ }^{2}$ and P.G. Krishna Mohan ${ }^{3}$ \\ ${ }^{1}$ Department of ECE, Aurora's Scientific \& Technological Institute, Hyderabad-500007, India \\ 2 Vice-Chancellor, Dr. Babasaheb Ambedkar Marathwada University, Aurangabad-431004, India \\ ${ }^{3}$ Department of ECE, JNTU College of Engineering, Hyderabad, India \\ majbbp@gmail.com, vijaympande@yahoo.com, pgkmohan@gmail.com
}

\begin{abstract}
In mobile communication, the transmission path from transmitter to receiver may be line of sight or may be obstructed by buildings, trees and mountains. The signal is received from multi path varies randomly with respect to time, frequency and distance from transmitter. Mobile video transceivers, which can transmit audio-visual messages, while on move, have got number of vital applications. To design a mobile transceiver, estimation of path loss is essential. There are number of propagation models to predict the path loss (Behera \& Das, 2008). However, there is a large variation in the path loss predicted using these models. These models are basically based on the data collected in parts of the globe other than India. To find out the path loss slope applicable for Indian suburban areas, the received signal strength is measured at various distances from the transmitter. For this, radiations from existing cellular mobile communication transmitters (base Stations) are used. The received signal strengths are then analysed and path loss slope is worked out. This path loss slope can be used to design mobile transceivers to be used in India and countries with similar environmental conditions.
\end{abstract}

Keywords: Mobile communication, Transmission path, India Introduction

In this modern era of multimedia communications, there are a number of applications of live audio-visual transmission. All of us enjoy live transmission of games, sports and other important activities across the globe. Generally all these transmissions are carried out using vehicle mounted trans-receivers. These mobile transreceivers are actually static when they are sending/ receiving. Generally satellite communication based VSAT equipment's are used. The antenna of the equipment is to be aligned to direction of the satellite antenna before transmission. In the recent past vehicle mounted VSATs with capabilities of communicating while on move have been developed. But, at times the vehicles could not reach the spot of activity like in case of floods, earthquakes etc. Propagation path loss forms an essential part of design calculations of any trans-receiver. Mobile transmitters (specially, man held) cannot transmit high powers to avoid health hazards of the operator. Radiation Safety level permitted is $0.08 \mathrm{~W} / \mathrm{Kg}$ for general population and $0.4 \mathrm{~W} / \mathrm{Kg}$ for occupational personnel (Pratt, 2007). If average man's weight is considered to be of $60 \mathrm{Kg}$, it works out for about $4.8 \mathrm{~W}$ for general population and about $24 \mathrm{~W}$ for occupational personnel. Correct estimation path loss is essential to optimize the transmitter power output.

Data summary of typical transceiver

There are number of models available to predict the path loss in cellular mobile communication environment (Behera\& Das, 2008; Rappaport, 2010). To understand, analyse and compare these models, specifications of a typical audio visual trans-receiver includes: Transmitter Antenna Height: 2m (Height of man); Transmitting Antenna: Omni Directional; Receiving Antenna:

Directional, $1 \mathrm{~m}$ dia-parabolic antenna with60\% efficiency; Height of receiving antenna: $6 \mathrm{~m}$; Frequency of operation: $2 \mathrm{GHz}$; T-R Separation: $15 \mathrm{Km}$ max.

Path loss calculations

Space propagation model: The free space power received by receiver antenna which is separated by a distance $\mathrm{d}$ from a transmitter is given by the Friis free space equation $\operatorname{Pr}(d)=\frac{P_{t} G_{t} G_{r} \lambda^{2}}{(4 \pi)^{2} d^{2} L}$

Where $d$ is the distance between transmitter and receiver, $\operatorname{Pr}(d)$ is the received power, $P_{t}$ is the transmitted power, $G_{t}$ is the transmitter antenna gain, $G_{r}$ is the receiver antenna gain, $L$ is the system loss factor not related to propagation ( $L \leq 1$, generally ) and $\lambda$ is the wave length in meters given by

$\lambda=\frac{c}{f}$

Where $f$ is the carrier frequency in Hertz and $c$ is the speed of light $\left(3 \times 10^{8} \mathrm{~m} / \mathrm{s}\right)$.

Free Space Path Loss is given by

$L_{F}=\frac{(4 \pi)^{2} d^{2} L}{\lambda^{2}}$

Free space path loss

Transmitter Power Output, $P_{t}=5 \mathrm{~W}=6.99 \mathrm{~dB}=$ $36.99 \sqcup 37 \mathrm{dBm}$.

Research article

COIndian Society for Education and Environment (iSee) 
$G=\frac{\left(4 \pi A_{e}\right)}{\lambda^{2}}$

$A_{e}$ is Effective Aperture area given by $A_{e}=\eta_{A} A$, where $\eta_{A}$ is the Efficiency of antenna, typically $0.6 \& A$ is actual area of the Aperture.

Area of Parabolic reflector antenna is given by $A=\Pi D^{2}$ Where $\mathrm{D}$ is the diameter of the antenna,

$\begin{aligned} & A=\pi x 1^{2}=\pi m^{2} \\ & \text { or } A_{e}=0.6 \pi=1.9 m^{2}\end{aligned} G=\frac{(4 \pi x 1.9)}{(o .15)^{2}}=1061=30 \mathrm{~dB}=60 \mathrm{dBm}$

Wave length, $\lambda=\frac{c}{f}=\frac{3 \times 10^{8}}{2 \times 10^{9}}=0.15 \mathrm{~m}$

Free space path loss as per (2.3), (where $L$ is the miscellaneous loss factor, generally 1 ), is

$L_{F}=\frac{(4 \pi)^{2}(15000)^{2}(1)}{(0.15)^{2}}=1.6 \times 10^{11}$

$L_{F}(d B)=10 \log 1.6 \times 10^{11}=112 d B=142 d B m$

Log-distance path loss model

Basic propagation models are based on theory of propagation or on ground measurement of signal strength. These models indicate that average signal strength power decreases logarithmically with the distance. This is found true for outdoor propagation or indoor.

The average path loss is given by (Rappaport, 2010)

$$
\begin{aligned}
& \overline{P L}(d) \propto\left(\frac{d}{d_{0}}\right)^{n} \\
& \overline{P L}(d B)=\overline{P L}\left(d_{0}\right)+10 n \log \left(\frac{d}{d_{0}}\right)
\end{aligned}
$$

Where $n$ is the path loss exponent, the rate at which path loss increases with distance, equals to 2 for free space and 4 for mobile environment?

$d_{0}$ is the close-in reference distance $\&$ is the T-R separation distance. Bar in (2.6) indicates ensemble average value.

Close-in reference distanceis also called as near field distance and given by

(Lee, 2006-1) as $\quad d_{0}=\frac{4 h_{1} h_{2}}{\lambda}$

Path loss as per log distance model: As per (2.7),

$d_{0}=\frac{4 h_{1} h_{2}}{\lambda}=\frac{4 \times 2 \times 6}{0.15}=320 \mathrm{~m}$
$\overline{P L}\left(d_{0}\right)$ is the free space path loss for near field distance and given by $\left(\frac{4 \pi R}{\lambda}\right)^{2}$ where $R$ is $320 \mathrm{~m}$.

$\overline{P L}\left(d_{0}\right)$ in $\mathrm{dBs}=10 \log \left(\frac{4 \pi \times 320}{0.15}\right)^{2}=88.56 \mathrm{~dB}$

and $10 n \log \left(\frac{d}{d_{0}}\right)=10 x 4 x \log \frac{15000}{320}=66.83 \mathrm{~dB}$

Total Path Loss $=(88.56+66.83)=155.39 \mathrm{~dB}=185 \mathrm{dBm}$

\section{Okumura model}

The Okumura model is the most widely used model for signal prediction in urban areas. This model is applicable for frequencies ranging from $150 \mathrm{MHz}$ to $3 \mathrm{GHzand}$ for distances up to $100 \mathrm{Km}$. The path loss using this model is given by

$P L(d B)=L_{F}+A_{m u}(f, d)-G\left(h_{t e}\right)-G\left(h_{r e}\right)-G_{A R E A}$

Where $L_{F}$ is the Free space path loss, $A_{m u}$ is the median attenuation relative to free space, $G\left(h_{t e}\right)$ is the transmitting antenna height gain factor, $G\left(h_{r e}\right)$ is receiving antenna height gain factor and $G_{A R E A}$ is the gain due to the type of environment.

This model is applicable for cellular mobile communication where transmitting (Base Station) antenna is at a height of about $200 \mathrm{~m}$ and receiving antenna is at about 3m (Rappaport, 2010). In case of mobile transmitter, it is man held, i.e., at about $2 \mathrm{~m}$ and receiver antenna (vehicle mounted) can be at a height, may be $6 \mathrm{~m}$ above the ground level.

Path loss as per Okumura model: Free space path loss $L_{F}$, in our case, as per para 2.1 is $112 \mathrm{~dB}$.

Median attenuation relative to free space $A_{m u}(f, d)$, over semi-smooth terrain is given in Okumura curves (Behera\& Das, 2008). For a frequency of $2 \mathrm{GHz}$ and for a T-R separation of $15 \mathrm{Km}$, it is approximately $34 \mathrm{~dB}$.

Transmitter antenna gain factor

$G\left(h_{t e}\right)=10 \log \left(\frac{h_{t e}}{3}\right)=10 \log \left(\frac{2}{3}\right)=-1.76 \mathrm{~dB}$

Receiver antenna gain factor

$G\left(h_{r e}\right)=20 \log \left(\frac{h_{r e}}{200}\right)=20 \log \left(\frac{6}{200}\right)=-30.45 d B$

For suburban area, $G_{A R E A}=9 d B$ 
Therefore, Path Loss as per

$P L(d B)=112+34-(-1.76)-(-30.45)-9$

$=169.21 \mathrm{~dB}=199.21 \mathrm{dBm}$

Hata model

The Hatamodel path loss data provided is valid from $150 \mathrm{MHz}$ to $1500 \mathrm{MHz}$. The frequency of operation, in this case, is about $2000 \mathrm{MHz}$. Therefore, Hata Model gives an approximate value of path loss. The formula for the path loss in urban areas is given by

$P L($ urban $)(d B)=69.55+26.16 \log f_{c}-13.82 \log h_{t e}$

$-a\left(h_{r e}\right)+\left(44.9-6.55 \log h_{t e}\right) \log d$

Where $f_{c}$ carrier frequency in $\mathrm{MHz}$ is, $d$ is the T-R separation distance in $\mathrm{Kms}$ and $a\left(h_{r e}\right)$ is the mobile antenna correction factor. For small to medium sized city, the factor is given by

$a\left(h_{r e}\right)=\left(1.1 \log f_{\mathcal{C}}-0.7\right) h_{r e}-\left(1.56 \log f_{\mathcal{C}}-0.8\right) d B$

(2.10)

Path Loss for Sub-urban areas is given by

$P L($ Sub - urban $)(d B)=P L($ urban $)(d B)-2\left[\log \left(\frac{f_{C}}{28}\right)\right]^{2}-5.4$

(2.11)

Path loss as per Hata model

Part (a) Urban areas: From (2.10),

$a\left(h_{r e}\right)=(1.1 \log 2000-0.7) 2-(1.56 \log 2000-0.8) d B$

$=5.862-4.349=1.5 d B$

From (2.9),

$P L($ urban $)(d B)=69.55+26.16 \log 2000-$

$13.82 \log 6-1.5+(44.9-6.55 \log 2) \log 15$

$=69.55+86.35-10.75-1.5+50.48$

$=194.13 \mathrm{~dB}=224.13 \mathrm{dBm}$

Part (b) Suburban areas

As per (2.11)

$P L($ Suburban $)(d B)=194.13-2\left[\log \left(\frac{2000}{28}\right)\right]^{2}-5.4=185.29 d B$

$P L($ Suburban $)=185.29 \mathrm{~dB}=215.29 \mathrm{dBm}$

PCS extension to HATA model

The European Cooperative for Scientific \& Technical research (EURO-COST) formed COST-231 working committee to develop an extended version of Hata Model. COST-231 proposed the following formula to extend Hata's Model to $2 \mathrm{GHz}$. The proposed model for path loss is

$P L($ urban $)(d B)=46.3+33.9 \log f_{c}-13.82 \log h_{\text {te }}$

$-a\left(h_{r e}\right)+\left(44.9-6.55 \log h_{t e}\right) \log d+C_{M}$

Where $C_{M}=0 \mathrm{~dB}$ for medium city $\&$ suburban areas
Vol. 5 No. 8 (August 2012) ISSN: 0974- 6846

$3 \mathrm{~dB}$ for metropolitan cities

The COST-231 extension of Hata Model is restricted to the following range of parameters:

$f: 1500 \mathrm{MHZ}$ to $2000 \mathrm{MHz}$

$h_{r e}: 30 \mathrm{~m}$ to $200 \mathrm{~m}$

$h_{t e}: 1 \mathrm{~m}$ to $10 \mathrm{~m}$

$d: 1 \mathrm{Km}$ to $20 \mathrm{Km}$

Path loss as per PCS extension to Hata model

Part (a) urban areas:

From (2.12),

( where $a\left(h_{r e}\right)=1.5 d B$ as per para 2.4)

$P L($ urban $)(d B)=46.3+33.9 \log 2000-13.82 \log 6-1.5$

$+(44.9-6.55 \log 6) \log 15+3$

$P L($ urban $)(d B)=46.3+111.67-10.75-1.5+46.8+3$

$P L($ urban $)=195.52 d B=215.52 d B m$

Part (b) Suburban areas: $C_{M}=0 \mathrm{~dB}$ for suburban areas and $3 \mathrm{~dB}$ for metropolitan cities. Therefore $P L($ suburban $)=195.52-3=192.52 .52 d B=222.52 \mathrm{dBm}$

Mobile point to point model (lee model)

Propagation Path Loss rate is generallyas under (Lee, 2006-1)

(a) Free space $\quad: 20 \mathrm{~dB} / \mathrm{dec}$

(b) Open area $: 43.5 \mathrm{~dB} / \mathrm{dec}$

(c) Suburban area : $38.4 \mathrm{~dB} / \mathrm{dec}$

(d) Urban area : may go up to $48 \mathrm{~dB} / \mathrm{dec}$

Generally path loss is about $40 \mathrm{~dB} / \mathrm{dec}$. But to ensure communication in adverse conditions it is taken as $40 \mathrm{~dB} /$ Oct. Then the General formula used for mobile radio propagation which could be for suburban area is given by (Lee, 2006-2)

$P_{r}=P_{t}-156-40 \log r_{1}+20 \log h_{1}+10 \log h_{2}+G_{t}+G_{m}$

(2.13)

Where

$P_{t}$ is the transmitted power on decibels above $1 \mathrm{~mW}$

$r_{1}$ is the T-R separation distance in miles

$h_{1}$ is the height of transmitting antenna in feet

$h_{2}$ is the height of receiving antenna in feet

$G_{t}$ is the gain of transmitting antenna in dBs

$G_{r}$ is the gain of receiving antenna in $\mathrm{dBs}$

Path loss as per lee model: From (2.13)

$P_{r}=10 \log 5000-156-40 \log \frac{15}{1.61}+20 \log 6(3.28)+10 \log 2(3.28)+0+10 \log 1061$ 
$P_{r}=36.99-156-38.7+25.88+8.17+0+30.26=-93.4 d \mathrm{Bm}$

$P L(\mathrm{dBm})=37-156-38.7=157.7 \mathrm{dBm}$

Summary of path loss

Table 1. Summary of path loss

\begin{tabular}{|c|l|c|}
\hline S No & \multicolumn{1}{|c|}{ Model } & Path loss $(\mathrm{dBm})$ \\
\hline 1 & Free Space Propagation Model & 142 \\
\hline 2 & Log-distance Model & 185 \\
\hline 3 & Okumura Model & 199 \\
\hline 4 & Hata Model & 215.29 \\
\hline 5 & PCS Extension to Hata Model & 222.52 \\
\hline 6 & Lee Model & 157.7 \\
\hline
\end{tabular}

From the Table 1, it is observed that the path loss for

$15 \mathrm{Km}$ at $2 \mathrm{GHz}$ varies from 142 to $222 \mathrm{dBm}$. It may be attributed to the following reasons:-

(a) Period of the reference books published varies from 2006 to 2010. During this period lot of changes took place in mobile communication. Initially all mobile phones were mounted on vehicles and had communication range of 10 miles or more. Therefore, path loss calculated may be applicable more for long distances.

(b) Mobile propagation is a multipath propagation and there are number of reasons for variations in the received signal strength. Variation of $8 \mathrm{~dB}(38 \mathrm{dBm})$ in $68 \%$ of the predicted value and actual value is considered as acceptable and called good estimation. It implies that for another $32 \%$ estimations, variations may be may be beyond $38 \mathrm{dBm}$ (Lee, 2006-1).

(c) The data collected to derive the formula may be from different countries having different climatic conditions. There is a need to ascertain the path loss applicable for Indian climatic conditions.

\section{Path loss measured in field}

Since there is no transmitter available for conducting this experiment, study has been carried out using the existing cellular mobile transmitters for voice/data communication, working in the area of interest.

Experimental setup
The signal strength was measured at various places using the following method: (a) A Laptop having the net monitoring software was used to monitor the signal strength. It gives, Cell Id, the signal strength in $\mathrm{dBm}$. (b) A GPS is used to find out latitude and longitude (Latlong) of any place, tower etc. It also gives the distance between any two places whose Latlong is known.

Field conditions

(a) Location:The Area of observations is in the outskirts of Secunderabad along Hyderabad- Karimnagar Highway and Kushaiguda- Keesara road. Both are Sub-urban Areas. (b) Atmospheric conditions: Dry, Normal Temperature of about 32 degree Celsius, Clear (c) Sky, Winter Season, between 10 AM and 4 PM. (d) Ground conditions: Approximately plain, with no hills etc. (e) Foliage: There is no dense forest. Only few trees here and there. (f) Rain: No rain was there during the observation period.

Service conditions

(a) Frequency of Operation: GSM $900 \mathrm{MHz}$

(b) Service Provider: Airtel

(c) Type of Service: Voice , 2G

(d) Band width of Channel: $4 \mathrm{KHz}$

(e) Tower Height: $10 \mathrm{~m}$ Approx.

\section{Experimental results}

Data obtained is given in Table 2.

Path loss slope calculations

The formula used for path loss slope calculation is as follows:

Path Loss (in $\mathrm{dB})=$ (Path Loss Slope) $\left(\log _{10}(\mathrm{~T}-\mathrm{R}\right.$ separation))

For Ex,Path Loss Slope $40 \mathrm{~dB} / \mathrm{dec}$ means path loss will be $40 \mathrm{~dB}$ if T-R Separation is increased by 10 times.

\section{Conclusions}

The path loss slope is varying from 34.6 to 44 . By averaging, the path loss slope is about $38.45 \mathrm{~dB} / \mathrm{dec}$. The Path loss slope found by field trials is tallying with Lee Model. Path loss calculated using other models is not

Table 2. Data of signal strength measured in field (suburban area)

\begin{tabular}{|c|c|c|c|c|c|c|c|c|c|}
\hline $\begin{array}{c}\mathrm{S} \\
\text { No }\end{array}$ & Cell Id & $\begin{array}{c}\text { BSIC } \\
(\mathrm{BCCH})\end{array}$ & $\begin{array}{l}\text { RSS } \\
\text { Idle } \\
(\mathrm{dBm})\end{array}$ & $\begin{array}{c}\text { RSS } \\
\text { Idle } \\
(\mathrm{dB})\end{array}$ & Latitude & Longitude & $\begin{array}{l}\text { Distance } \\
\text { between } \\
\text { serial Nos }\end{array}$ & $\begin{array}{c}\text { distance } \\
\text { from Cell } \\
\text { site(Km) }\end{array}$ & $\begin{array}{c}\text { Path loss } \\
\text { slope } \\
(\mathrm{dB} / \mathrm{dec})\end{array}$ \\
\hline 1 & 6001 & $01(56)$ & -54 & -24 & 17.55971 & 78.54453 & - & 0.5 & - \\
\hline 2 & 6001 & $01(56)$ & -75 & -55 & 17.56688 & 78.55403 & $1-2$ & 1.79 & 37.9 \\
\hline 3 & 6001 & $01(56)$ & -86 & -56 & 17.57373 & 78.56593 & $2-3$ & 3.27 & 42 \\
\hline 4 & 6001 & $01(56)$ & -97 & -67 & 17.59774 & 78.56861 & $3-4$ & 6.69 & 35.4 \\
\hline 5 & 50821 & $52(41)$ & -82 & -52 & 17.57373 & 78.56596 & - & 3.0 & - \\
\hline 6 & 50821 & $52(41)$ & -87 & -57 & 17.58003 & 78.57456 & $5-6$ & 4.15 & 35 \\
\hline 7 & 50822 & $21(37)$ & -75 & -45 & 17.57373 & 78.56593 & - & 1.5 & - \\
\hline 8 & 50822 & $21(37)$ & -84 & -54 & 17.58003 & 78.57456 & $7-8$ & 2.65 & 36 \\
\hline 9 & 843 & $56(38)$ & -61 & -31 & 17.59774 & 78.56861 & - & 1.0 & - \\
\hline 10 & 843 & $56(38)$ & -78 & -50 & 17.61108 & 78.57073 & $9-10$ & 2.5 & 42.7 \\
\hline 11 & 53212 & $10(35)$ & -74 & -44 & 17.62159 & 78.57121 & - & 1.5 & - \\
\hline 12 & 53212 & $10(35)$ & -84 & -54 & 17.61239 & 78.57198 & $11-12$ & 2.53 & 44 \\
\hline 13 & 37121 & $15(39)$ & -78 & -48 & 17.50498 & 78.62689 & - & 1.5 & - \\
\hline 14 & 37121 & $15(39)$ & -90 & -60 & 17.51267 & 78.64190 & $13-14$ & 3.33 & 34.6 \\
\hline
\end{tabular}

BSIC - Base Station Identity Code; $\mathrm{BCCH}$ - Broadcast Channel

Research article

Clndian Society for Education and Environment (iSee)
"Mobile communication" http://www.indjst.org
Bhikshapathy et al. Indian J.Sci.Technol. 
tallying with Lee model. Lee model shall be used for all path loss calculations for Indian Suburban areas. However, this is not inclusive of foliage loss, rain attenuation or adverse terrain/ climatic conditions, which have to be calculated separately.

Acknowledgement

The authors express their heartfelt gratitude to Col. K.P.C. Rao, Col H.G. Malude and Major T.K. Balakrishnan of M/s Aster Teleservices, Hyderabad, for their technical support in measuring the signal strength in field.

References

1. Behera GK and Lopamudra Das (2008) Mobile communication. pp: 13-33.

2. Lee (2006) Wireless and cellular telecommunications. III Ed. pp: 363.

3. Lee WC (2006) Mobile cellular telecommunications. Analog \& Digital Sys. // Ed .pp: 104-110.

4. Pratt T, Bostian C and Allnut J (2007) Satellite communications. II Ed. pp: 102, 420.

5. Rappaport TS (2010) Wireless communications. Principles \& Practice. II Ed. pp: 107-154. 